\title{
Investigating the Intertwinement of Knowledge, Value, and Experience of Upper Secondary Students' Argumentation Concerning Socioscientific Issues
}

\author{
Carl-Johan Rundgren ${ }^{1}$ - Martin Eriksson ${ }^{2}$. \\ Shu-Nu Chang Rundgren ${ }^{2,3}$
}

(C) The Author(s) 2016. This article is published with open access at Springerlink.com

\begin{abstract}
This study aims to explore students' argumentation and decision-making relating to an authentic socioscientific issue (SSI) - the problem of environmental toxins in fish from the Baltic Sea. A multi-disciplinary instructional module, designed in order to develop students' skills to argue about complex SSI, was successfully tested. Seven science majors in the final year of their upper secondary studies participated in this study. Their argumentation and decision-making processes were followed closely, and data were collected during multiple stages of the instructional module: group discussions were audio recorded, the participants wrote reports on their decision making, and postexercise interviews were conducted with individual students. The analysis focused on the skill of evaluation demonstrated by the students during the exercise and the relationships between the knowledge, values, and experiences that they used in their argumentation. Even though all of the students had access to the same information and agreed on the factual aspects of the issue, they came to different decisions. All of the students took counter-arguments and the limitations of their claims into account and were able to extend their claims where appropriate. However, their decisions differed depending on their background knowledge, values, and experiences (i.e., their intellectual baggage). The implication to SSI teaching and learning is discussed.
\end{abstract}

Carl-Johan Rundgren

carl-johan.rundgren@mnd.su.se

Martin Eriksson

vintergatan15@hotmail.se

Shu-Nu Chang Rundgren

shu-nu.chang-rundgren@edu.su.se

1 Department of Mathematics and Science Education, Stockholm University, SE-106 91 Stockholm, Sweden

2 Department of Engineering and Chemical Sciences, Karlstad University, 65188 Karlstad, Sweden

3 Department of Education, Stockholm University, SE-106 91 Stockholm, Sweden 


\section{Introduction}

Several recent studies conducted in various countries have examined students' argumentation relating to controversial socioscientific issues (SSI) in science classrooms (e.g., Driver et al. 2000; Erduran et al. 2004; Sadler 2004). It can be beneficial to discuss SSI during science teaching both because it encourages students to see science as something that is relevant (e.g., Chang Rundgren and Rundgren 2010; Stuckey et al. 2013) and also to prepare students for life as citizens in a society that is often confronted by new and controversial science-related issues (Sadler and Zeidler 2005). From the perspective of educating the citizens of tomorrow, it is important for students to develop skills that will allow them to argue constructively about illstructured and complex issues so as to establish a critical awareness of the diverse perspectives associated with them (Sadler et al. 2007).

Previous science education studies concerning argumentation on SSI have explored several different aspects of knowledge and value. Nielsen (2012a) has made a distinction between studies focusing on the presence and quality of science content in socioscientific deliberations and studies focusing on the extent to which students' science knowledge or knowledge about science determines the quality of their socioscientific deliberations. Kolstø (2001) has argued that because decision-making on socioscientific issues is value-based, we do not know to what extent knowledge of science can improve the decision-making process. Levinson (2006) has shown that evidence can have different roles in different cases and that scientific evidence may not play any major role in the resolution of some issues, for instance when participants in the debate have fundamentally different views or values.

According to Rudolph (2005), public discourse on scientific literacy traditionally focuses on how science can inform decision-making about societal issues related to the environment, health, energy policy, etc., and on the value of scientific thinking to individuals in their everyday lives. This discourse emphasizes the flow of information from science to the public rather than in the opposite direction. The idea that the ultimate goal of the pursuit of science is to benefit human life and society is not always clearly emphasized in discourses that focus on pure science. Drawing on Dewey's (1916) pragmatic philosophy and the instrumental value of science as something that serves societal needs rather than an intellectual edifice in its own right, Rudolph has emphasized the importance of using social issues as a starting point for discussion in science teaching. Several recent studies on informal reasoning and argumentation skills in the context of SSI have adopted a different emphasis: instead of focusing on scientific knowledge (e.g., Fleming 1986), they have investigated how individuals' values and experiences contribute to their decision-making concerning SSI (Chang and Chiu 2008; Christenson et al. 2012; Kolstø 2006; Sadler and Zeidler 2005; Eriksson and Rundgren 2012), as well as the role of multi-disciplinary viewpoints in argumentation concerning SSI (e.g., Chang Rundgren and Rundgren 2010; Morris 2014). Notably, Chang Rundgren and Rundgren (2010) have emphasized the importance of considering SSI holistically. To facilitate such holistic analysis, these authors developed the SEE-SEP (the abbreviation intends to reflect the multi-disciplinary nature of SSI with the six subject areas of Science, Environment, Ethics, Social/culture, Economy and Policy) model to describe how people form opinions and make decisions about SSI. In addition to the above-mentioned six subject areas, this model includes the three aspects of knowledge, values, and experiences, which were found in people's SSI argumentation (Chang Rundgren and Rundgren 2010). The aspects relate to the individual's background and personal life history, while the subject areas reflect different sources of information and more impersonal considerations. The advantage of exploring SSI in the 
science classroom is that it provides an opportunity to convey scientific knowledge while also making students aware of the complexity of SSI and helping them to develop skills to function as citizens in democratic society by discussing and evaluating different viewpoints on specific SSI (Chang Rundgren 2011; Sadler and Zeidler 2005).

To meet the need for methods that address the multi-disciplinary nature and complexity of SSI in school science, based on a multi-disciplinary SSI instructional model (Chang Rundgren 2011), a six-step SSI instructional module was developed and presented in this study with the aim of encouraging students to exercise their roles as citizens in the science classroom and enhancing their skills associated with SSI argumentation. By using a complex societal issue, which involves several aspects and different interest groups, the instructional module was constructed with the intention to increase students' awareness of the complexity of SSI. This article focuses on the relationships between students' knowledge, values, and experiences as revealed by their argumentation concerning the case of environmental toxins in fish from the Baltic sea - an issue on which people's opinions are influenced by environmental, health, policy, cultural, and economic considerations as well as scientific data. The article intends to characterize students' argumentation and how they use certain knowledge, values, and experiences in their arguments.

\subsection{Modeling Students' SSI Argumentation}

The nature of SSI argumentation can be discussed and represented in several ways. The most widely used model of argumentation, formulated by Toulmin (1958), states that most arguments have six distinct components: grounds, warrant, backing, qualifiers, claim, and rebuttal. Toulmin's argument pattern (TAP) has been used to develop a framework for assessing the quality of argumentation (Erduran et al. 2004; Osborne et al. 2004). In this framework, the use of rebuttals is seen as an important indicator of quality. However, the TAP-based framework primarily assesses the quality of argumentation with reference to the structure of the arguments presented and the skill with which they are made rather than their content (Chang and Chiu 2008). More recently, several researchers have found that it can be difficult to clearly distinguish between the nominally separate elements of Toulmin's model while analyzing SSI argumentation (e.g., Chang and Chiu 2008; Kelly et al. 1998; Nielsen 2013). From a pilot study on analyzing students' SSI argumentation, Chang and Chiu (2008) have addressed the "informal" feature of SSI argumentation, which is in line with the results derived by Kelly et al. (1998), who contend that Toulmin's model is too clear-cut ("formal") and cannot fully describe the complexities of SSI argumentation. The informal and dialectical feature of SSI argumentation was also emphasized in a review article done by Nielsen (2013).

As an alternative to Toulmin's model, Chang and Chiu (2008) adopted Lakatos' scientific research programs (Lakatos 1978) to analyze students' skills of informal argumentation. Although some of the problems of distinguishing the elements in the TAP model may also be found in Chang and Chiu's (2008) adoption of the Lakatos model, the latter may still provide some advantages in studies of argumentation. The idea, expressed in the model, that the argument has a hard core, which is surrounded by a protective belt, can be used to identify central or decisive aspects of an argument and distinguish those from aspects that mainly are used to protect the hard core and to evaluate the pros and cons of the main claim (i.e., the positive and negative heuristics). Furthermore, the model has also proven to be suitable for use in teaching and learning about SSI and the skill of argumentation (Chang Rundgren 2011), and for assessing the quality of SSI-argumentation (Christenson and Chang Rundgren 2015). 
Regardless of the model used to analyze SSI argumentation, it has been suggested that informal argumentation on SSI relies on five key skills (Chang and Chiu 2008). The relation between these five skills and Lakatos' scientific research programs is shown in Table 1. In Chang and Chiu's model, the protective belt $(\mathrm{PB})$ surrounding the hard core $[\mathrm{HC}]$ includes the positive and negative heuristics ( $\mathrm{PH}$ and $\mathrm{NH}$, respectively), which connect to the ability to argue in relation to an awareness of the limitations of the claim, as well as to possible extensions of the claim. These skills together form the ability to evaluate arguments.

In Chang and Chiu (2008, p. 1763), we find some examples of how their adoption of the Lakatos model is used to analyze students' arguments. For example, one student made the claim: "I would love to eat organic food" $[\mathrm{HC}]$, but she moderated this claim saying "However, the price is too high in Taiwan and not so many people can afford it" [NH]. Later, the student further explained that "I think our government should subsidize the farmers and make the price of organic food lower" [PH].

The skill of evaluation varies with a person's attitude, beliefs, knowledge, and/or values in terms of different topics (Means and Voss 1996; Voss and Means 1991) and has been shown to be difficult to develop (e.g., Chang and Chiu 2008). In many cases, people tend to weigh positive reasons more heavily than negative reasons (Shafir et al. 1993). We were therefore particularly interested in studying the development of the evaluation skills of the students who participated in our six-step SSI instructional module. Using the terminology of Chang and Chiu's adoption of the Lakatos model (Table 1), our analysis focuses on the protective belt (PB) of students' SSI argumentation, in which the use of positive and negative heuristics (PH and $\mathrm{NH}$, respectively) is included, in order to determine whether participation in the six-step instructional module induced the students' skills of evaluation. The process by which individuals make decisions on SSI is discussed in more detail below.

\subsection{Decision-Making on SSI}

Informal reasoning is generally acknowledged to play a fundamental role in SSI-related decision-making (e.g., Sadler 2004; Sadler and Zeidler 2005; Wu and Tsai 2007). Informal argumentation, which is more complex, open, and unstructured than formal argumentation, has similarly been claimed to be important in the resolution of SSI (e.g., Chang and Chiu 2008). Multiple recent studies have discussed the differences between formal and informal

Table 1 Relationship between Lakatos' programs and the five indicators of informal argumentation (After Chang and Chiu 2008, p.1758)

\begin{tabular}{lll}
\hline Components of Lakatos' programs & Skills of informal argumentation & Definition \\
\hline Hard-core (HC) & $\begin{array}{l}\text { (1) Making claims } \\
\text { (2) Providing supporting reasons }\end{array}$ & $\begin{array}{l}\text { Individuals could provide their } \\
\text { own claim supporting by one or } \\
\text { more reasons. } \\
\text { Negative heuristic (NH) }\end{array}$ \\
$\begin{array}{lll}\text { Based on the claim, individuals } \\
\text { could know the limitation of the } \\
\text { claim they made. }\end{array}$ \\
Positive heuristic (PH) & (4) Showing qualifiers & $\begin{array}{l}\text { Based on the claim, individuals } \\
\text { could know the progress or the } \\
\text { extension of the claim. } \\
\text { Individuals could evaluate } \\
\text { arguments. }\end{array}$ \\
\hline
\end{tabular}


reasoning and argumentation (Chang and Chiu 2008; Wu and Tsai 2007). Formal reasoning is widely used in science education, which is heavily reliant on deductive reasoning concerning well-structured problems under fixed premises, often characterized by the rules of logic and mathematics. For example, students frequently solve textbook problems in physics by using readily accessible and unambiguous information that is compatible with existing scientific knowledge, under clearly stated premises. Conversely, when informal reasoning is used, the problems to be solved are always ill-structured and more complex, there is much less authoritative or unambiguously reliable information available, and there is no single set of well-defined and clearly stated premises. The premises used in informal reasoning are strongly dependent on individuals' personal knowledge, values, attitudes, and beliefs (Means and Voss 1996) and on information from different sources (e.g., newspapers, Internet, everyday experiences) (Chang and Chiu 2008). SSI-related argumentation and decision-making thus involve a process of informal reasoning that requires participants to seek out and evaluate information, construct arguments to support claims, and then evaluate those claims by considering supporting arguments and counterarguments in order to reach a conclusion about what actions should be taken.

Readily-accessible scientific knowledge is required to enable well-founded decision-making concerning SSI questions. However, it has been demonstrated that SSI decisions are made on the basis of individual judgment and value-based reasoning rather than knowledge alone (Chang Rundgren and Rundgren 2010; Nielsen 2012b; Kolstø 2006; Bell and Lederman 2003; Grace and Ratcliffe 2002; Sadler and Zeidler 2005). Kolstø (2006) found that some types of knowledge and values - "decisive knowledge" and "decisive values"-are particularly important for individual students' decision-making on SSI and suggest that the question is not whether knowledge is relevant for making policy decisions but what kind of knowledge is regarded as relevant by people with different values. As an example, based on the same knowledge base, one individual could argue that nuclear power should be used because of its energy efficiency, while another individual would argue that nuclear power should not be used because of the risk of accidents with far-reaching consequences. Kolstø further argues that an individual's opinion or decision on an issue may be based on several arguments and their evaluation of the arguments for and against their decision. As such, SSI-related decisions are dependent on personal values and their impact on the evaluation of arguments with different pros and cons (Kolstø 2006). SSI argumentation and decision-making therefore involve evaluating information and knowledge as well as value-based reasoning, which might be implicit in the argumentation process (Means and Voss 1996; Voss and Means 1991). Personal decisions in such cases cannot be predicted by logical reasoning alone because of their dependence on individuals' ideological standpoints and personal principles (Nielsen 2012a). Acar et al. (2010) have concluded that the problem is not that people use value-based reasoning in SSI contexts so much but their sometimes limited awareness of the extent to which they rely on it.

Zeidler (1997) has described as "intellectual baggage" the previously established cognitive and moral beliefs that students bring to the classroom. These cognitive and moral beliefs can be defined as deeply rooted, abstract motives which guide and motivate a person's attitudes, norms, views, and actions (Davidov et al. 2008). Sadler and Zeidler (2005) have made a distinction between three different patterns of integrated informal reasoning among students: rationalistic, intuitive, and emotive. Rationalistic informal reasoning is described as a form of cognitive reasoning in which the participants rely exclusively on reason and logic to support their positions. Intuitive informal reasoning is a process whereby participants make decisions 
primarily based on their immediate feelings or reactions. Finally, emotive informal reasoning involves both cognition and affection. Sadler and Zeidler (2005) further noted that while students often used combinations of these methods of argumentation, intuitive reasoning tended to dominate over the other methods whenever it was used. When dealing with SSI, a strong intuitive reaction (which is reflected in the position an individual adopts at the start of the decision-making process) may indicate that the SSI in question has some bearing on the individual's intellectual baggage. However, we should also bear in mind that there is criticism against a division of reasoning based on "reason" and "affection" (e.g., Railton 2014), and that it may from some perspectives be an over-simplification of the complex processes of human reasoning.

Liu et al. (2011) have stated that in decision-making processes, individuals tend to be most convinced by the solutions that are most closely aligned with their existing knowledge and personal convictions. Evagorou et al. (2012) studied the decision-making processes of a group of students and found that they tended to make decisions quickly and then selectively focus on evidence that supported those decisions while ignoring other data. These authors also conclude that students' decisions were based on their ability to identify with actors associated with the issue and their pre-existing preferences (if any) for those actors. This result was consistent with previous studies on SSI argumentation (e.g., López-Facal and Jiménez-Aleixandre 2008; Simonneaux and Simonneaux 2009). In keeping with these observations, Zeidler (1997) has concluded that students tend to use information that aligns with their convictions and ignore contradictory evidence, which is also in line with the results of Chang and Chiu (2008), indicating that negative heuristics were often ignored in students' informal argumentation on SSI.

Regardless of the extent to which knowledge and values are involved in students' SSI argumentation, several studies have highlighted the importance of encouraging students to develop a meta-awareness of their own SSI-related decision-making processes. For instance, Oulton et al. (2004) have argued that the main potential outcome from the use of SSI-based teaching is not to improve the students' decision-making per se but to foster an understanding of the nature of controversial issues and instill open-mindedness, a thirst for additional information, and the ability to identify bias and reflect critically. The six-step SSI instructional module presented in this study is constructed with the intention to enhance students' evaluation skills associated with SSI argumentation and to thereby increase their meta-awareness of the complexity of SSI and the existence of multiple perspectives on such complex issues.

\subsection{Aim and Research Questions}

The studies cited in the preceding sections have amply demonstrated that students tend to rely on value-based arguments when engaging in SSI argumentation. This makes it important to structure teaching in a way that gives students opportunities to reflect on their values (and those of others) in relation to science. This can be done via SSI education. Using Zeidler's (1997) notion of "intellectual baggage," the three aspects of knowledge, value, and experience (Chang Rundgren and Rundgren 2010), and Kolstø's (2006) concepts of "decisive knowledge" and "decisive values" to describe central aspects of the students' argumentation, this study investigates the influence of intellectual baggage (i.e., prior knowledge, values, and past experiences) on the SSI argumentation of students participating in the newly developed six-stage SSI instructional module. It is known that in certain contexts, this intellectual baggage can play a dominant role in decision-making. However, the extent of this dominance 
can be influenced by the framing of the teaching context and the interactions between the teaching context and the students' intellectual baggage. The nature of the SSI under discussion and/or the information provided by the teacher may touch on certain deep-rooted values and/or students' memories of past experiences. All these may affect students' evaluation of information and their selection of knowledge or data that may in turn strongly affect their ultimate decision concerning the SSI. Naturally, some issues may not relate to an individual student's intellectual baggage in any meaningful way. In such cases, it seems likely that a student's decision will be made from a more purely intellectual standpoint by considering the available information and evidence rather than being predominantly guided by values and experiences.

Based on the results of previous studies (Chang and Chiu 2008; Chang Rundgren and Rundgren 2010; Christenson et al. 2012; Eriksson and Rundgren 2012; Christenson et al. 2014; Kolstø 2006; Zeidler 1997), we assume that the decisive knowledge, values, and experiences interact to drive students' decision-making on SSI. Based on the decisive values and/or experiences, students select information (the decisive knowledge) to support their decisions and then construct informal arguments concerning the SSI in question (Kolstø 2006). The specific aim of this study is to explore the factors that govern students' SSIrelated decisions by observing the decision-making process of a small number of students participating in an SSI teaching program. The study's research questions are as follows:

(1) How can students' skills of argumentation in the SSI instructional module be characterized?

(2) How do decisive knowledge, decisive values, and decisive experiences interact and influence students' decision-making on SSI?

\section{Methods}

The focus of this study is to explore students' skills of SSI argumentation (with particular emphasis on skills of evaluation) and to clarify the relationships between decisive values, knowledge, and experiences in SSI decision-making. A qualitative method was deemed optimal for these purposes because it would enable us to describe in detail individual students' argumentation and the processes by which they evaluated complex open-ended problems, without being influenced by limiting a priori hypotheses. Data on the argumentation and decision-making of seven upper secondary school students were collected by monitoring group discussions, examining individual written arguments, and conducting individual interviews after the students had completed the SSI instructional module.

The latest version of the Swedish curriculum for upper secondary school (Swedish National Agency of Education 2011) emphasizes the training of argumentation skills, also in science. Thus, all students in upper secondary school need to train in argumentation. Seven students (4 males and 3 females) from a science-major program at an upper secondary school in Sweden were invited to participate in a decision-making exercise focusing on the issue of environmental toxins in fatty fish from the Baltic Sea. The study was conducted during the last semester of the upper secondary school period. Since the SSI in question could be characterized as relatively complex, we chose to work with students with a strong academic background. Besides, our view is that all students can potentially benefit from working with these kind of complex issues at some point. 
The students consisted of a complete group of students attending a course. All of the students are referred to by pseudonyms in this article. The data was collected in a classroom setting; the second author was known to the students as a science teacher and acted as both an instructor and a researcher during this study. To prevent the introduction of bias due to the second author's relationship with the students, we adopted a student-centered design in the SSI instruction so that students could hold discussions within the classroom in the second author's absence. It is important to note that this is an exploratory study, and we admit that the generalization of our results is limited with only seven participating students in the study. However, the limited number of participants enabled us to follow the development of their arguments and eventual decisions in more detail. Since the participants were science majors in their last year of secondary education, they could represent a high achieving group among Swedish upper secondary students. Future studies using the same module could benefit from exploring the possibility of working with other groups of students.

\subsection{The SSI Context Used in This Study: Environmental Toxins in Fish from the Baltic Sea}

The accumulation of environmental toxins in fish from the Baltic Sea is an authentic sciencerelated sociopolitical issue that concerns toxic organic chemicals and sustainable development. In 2011, the Swedish National Food Agency released a report stating that high levels of dioxins had been found in certain species of fatty fish in the Baltic Sea such as Baltic herring and wild salmon. Dioxins are lipophilic persistent organochlorine compounds that are considered to pose serious health risks in humans and other species. Among other things, they have been linked to cancer, immune and nervous system disorders, liver damage, and sterility. To ensure the health and safety of EU consumers, the European Commission established regulations in 2002 that imposed an upper limit on the dioxin contents of foods. Any food whose dioxin content exceeds this limit may not be marketed in the EU. Therefore, fatty fish (mostly herring and salmon) from the Baltic can no longer be sold on the European market.

Sweden, Finland, and Latvia currently have exemptions from the EU legislation on dioxins for certain fish species from the Baltic Sea. This permits fish whose dioxin content exceeds the threshold to be marketed within these countries but not exported. Sweden's exemption was made permanent in 2011 based on the condition that the Swedish National Food Agency (Sweden's central administrative authority for matters concerning food) would be able to disseminate information regarding the risks such fish present to certain groups of people (i.e., children, pregnant women and girls of fertile age, and presumed high consumers) among the Swedish population (Swedish National Food Agency 2011). According to the Swedish government, this exemption is of national importance because it provides job opportunities and ensures that rural coastal areas remain livable while also protecting the Swedish tradition of eating fermented herring.

The decision to seek a permanent exemption was controversial. Public surveys have shown that despite the ongoing efforts of the Swedish National Food Agency, a majority of the Swedish population is unaware of key parts of the recommendations about consuming fatty fish from the Baltic Sea. In fact, the Swedish National Food Agency has criticized the decision to adopt a permanent exemption and concluded that the exemption has put thousands of children and women in the Swedish population at risk of exceeding the safe dioxin threshold, because the agency has not been able to disseminate information about the risks (Swedish National Food Agency 2011). 


\subsection{The Six-Step SSI Instructional Module Developed in This Study}

The seven students were asked to discuss and study the issue of dioxin contamination in fatty fish over 4 weeks. To facilitate the systematic exploration of SSI and to foster students' argumentation skills in a classroom setting, we developed a six-step instructional module (Fig. 1). The instructional module is inspired by a cross-disciplinary approach to teaching SSI named "Post it" (Chang Rundgren 2011) and has earlier been described (in German) in Rundgren and Eriksson (2014). The participating students had previously participated in another SSI teaching module concerning a mining issue and were thus familiar with the procedure adopted in this study. The content and progression of the module's six steps were judged to provide favorable conditions for encouraging students to engage in what Sadler and Zeidler (2009) described as desirable practices for decision-making in the context of SSI: (1) recognizing the inherent complexity of SSI; (2) examining issues from multiple perspectives; (3) appreciating that SSI are subject to ongoing inquiry; and (4) exhibiting skepticism when presented with potentially biased information. The six steps of the SSI instructional model are shown in Fig. 1.

In step 1, the teacher presents the SSI to be discussed, its scientific aspects, and any instructions that the students require. In this step, the teacher has to inform the students about the issue, explain its importance, and make the students aware of its complexity by outlining the multiple perspectives surrounding it. At the end of the presentation, the students are faced with a clear yes or no question. In this case, the question given to students was as follows: Did the Swedish government make the right decision when it adopted a permanent exemption from the EU regulations governing dioxin levels in fatty fish from the Baltic Sea? The pedagogical reason to make the students come up with a clear yes or no answer to this indeed complex issue, involving many aspects and interests, was mainly to develop their ability to acquire complex information and make use of it in such a way that they were able to reach a specific decision. Also, later in life as citizens, they may find themselves facing a clear yes or no question to a complex societal issue, for instance in a referendum.

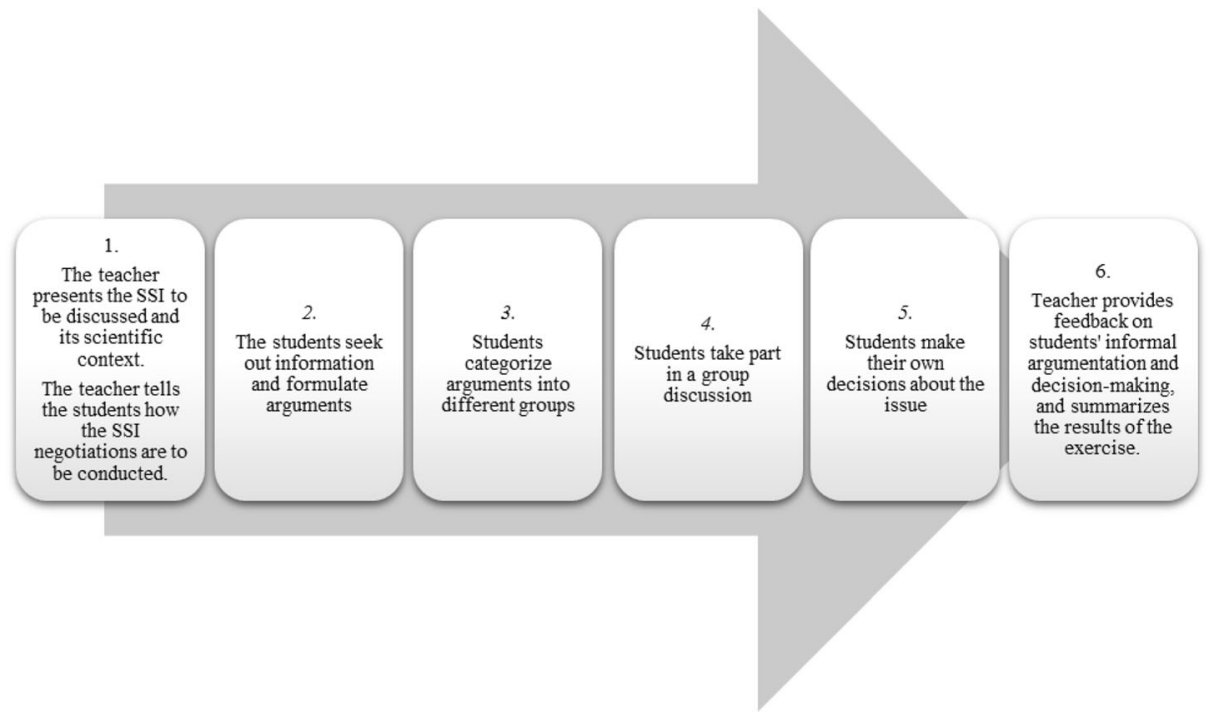

Fig. 1 The six steps of the SSI instructional model 
In step 2, students seek out additional information and formulate arguments. After being organized into groups, the students seek out relevant information, start to discuss the different perspectives on the issue, and formulate as many arguments (with supporting reasons and evidence) as possible. In the Baltic Sea exercise, the students were divided into one group of four and one group of three. Each group is given sets of two-colored sticky notes ("post it" notes) on which to write down their arguments and supporting reasons. At the end of step 2, the teacher makes copies of each group's sticky notes and hands the copies to the other group.

Then, in step 3, students categorize arguments into different groups. When the students have written down their arguments on the sticky notes, they stick them on a whiteboard and begin to group the notes, assigning names of their own choosing to different groups of arguments. The aim of this activity is to let the students visualize the multidimensional aspects of SSI and give them an instrument to facilitate subsequent group discussions.

In step 4, students take part in a group discussion based on their visual representation of the issue's complexity on the whiteboard. This allows students to express and evaluate ideas and develop expertise in using collaboration and informal reasoning to resolve real community issues.

In step 5, students make their own decision about the issue. After the end of the group discussion, students are asked to individually express their opinions on the issue and come to a decision. The students complete and submit a form on which they answer the yes or no question mentioned in the description of step 1 and explain how and why they chose the answer they did. The form given to the participating students in the Baltic Sea exercise included the following question and tasks:

- Do you agree or not agree that Sweden should have a permanent exemption from the EU regulations on dioxin levels for fatty fish from the Baltic Sea?

- Write down and rank the four most important supporting reasons for your decision.

- Write a brief argumentative text (about 500 words) describing your decision and the factors that motivated it.

Finally, in step 6, the teacher provides feedback on students' informal argumentation and decision-making, and summarizes key points arising from the exercise. Here, the teacher concludes the exercise, summarizes its results, and gives feedback concerning the students' expression of the issue's multidimensional aspects, their informal reasoning, and their use of varied supporting reasons in their decision-making.

Kolstø's (2006) study of students' decision-making concerning the construction of overhead power transmission lines indicated that the participating students found it difficult to seek out additional information on their own. It was therefore suggested that future frameworks for argumentation and decision-making should give students easy ways of finding relevant information and viewpoints. We considered it important to provide the students with a wide range of information relevant to the issue at hand (i.e., the dioxin contamination of Baltic Sea fish). To this end, the students were given representative information from different sources (newspapers, associations, authorities, etc.) representing diverse viewpoints. In addition to the general information provided by the teacher in step 1, the students were also given written information from the Swedish National Food Agency about the chemical and toxic properties of dioxins, the current recommendations concerning fish consumption issued, the justifications for the government's decision to adopt an exemption from the EU's regulations, and some 
debate articles from the Swedish Society for Nature Conservation and Swedish daily newspapers that critically question the exemption.

It was also important to ensure that all students possessed the same information and were aware of the same range of viewpoints. This was ensured by the collaborative group activities in steps 2 and 3, and the exchange of viewpoints between the groups by the copying and transfer of their post it notes. During the development of our instructional model, we recognized that informal argumentation exists in both individualistic and social forms and that social aspects are essential when negotiating ongoing debates concerning sociopolitical issues that involve science. In this aspect, we share the view of Kolstø and Ratcliffe (2007) that argumentation is basically social and operates in a social context. The focus on contradiction in argumentation was first presented by the Greek Sophist philosophers such as Protagoras, who claimed that to every single argument, there is always a counter-argument (dissoi logoi), and that valid arguments are explicit arguments that have been confronted and withstood counterarguments in dialectical debates (Kolstø and Ratcliffe 2007). This important dialectical feature of socioscientific deliberations has been emphasized, inter alia, by Nielsen (2013), who has claimed that socioscientific deliberations involve practical arguments about what to do and must therefore be categorized as a form of dialectical argumentation.

\subsection{Data Collection}

Data were collected during different steps of the SSI exercise by (1) audio-taping and transcribing the group discussions conducted during step 4, (2) analyzing students' written reports produced during step 5, and (3) audio-taping and transcribing semi-structured postexercise interviews with individual students.

Group discussions were conducted in two separate groups of three or four students during step 4 of the SSI exercise. Each group performed their discussion in front of their own visual representation of the complexity of the issue, which they created by grouping sticky notes representing different arguments and pieces of supporting evidence on a whiteboard during step 3. The students were instructed to discuss and evaluate every single argument and perspective they had on the whiteboard, on their own. To facilitate informal communication and consolidate social interactions in the groups, one student was appointed as a moderator in each group. The discussions were audio taped and the teacher interfered as little as possible while they progressed. There were no time limits on the discussions and the students decided on their own when they considered the discussion task to be completed.

To explore different individual patterns of informal argumentation and decision-making and thereby identify individual students' decisive values and knowledge, it was important to ensure that the students expressed their own opinions and decisions individually. This was achieved by asking the students to complete and submit a "decision-making form" on which each student stated their decision and justified their choice. These forms asked students to answer a yes/no question about whether the Swedish government was right to adopt a permanent exemption from EU regulations on dioxin levels for fatty fish from the Baltic Sea, to write down and rank the four most important reasons supporting their decision, and to write a brief argumentative essay explaining their decision and presenting their supporting reasons and justifications in more detail. About two weeks after the students submitted their decisions, each student was interviewed individually by the second author. The interviews were audio-taped and conducted at the students' school. During these semi-structured interviews, they were asked to reflect on the entire SSI experience, with particular emphasis on the evolution of their 
own views on the issue in question, and their decision-making process during the SSI module. In addition, they were asked to assess at what stage in the exercise their standpoints emerged, and how their thoughts about these early standpoints evolved over the course of the exercise, with particular reference to the effects of the dialectical group discussion on their decisionmaking. The audio-taped discussions and individual semi-structured interviews were all completely transcribed for further analysis.

\subsection{Data Analysis}

As mentioned in 1.1, the skill of evaluating arguments is difficult to develop (Chang and Chiu 2008). We therefore wanted to see whether our new SSI instructional module was effective at enhancing students' skills in evaluating arguments. Based on the analytical framework of Chang and Chiu (2008), we analyzed the students' skills of evaluation by assessing their recognition of the limitations of their own claims (negative heuristics, $\mathrm{NH}$ ) and their ability to extend those claims (positive heuristics, $\mathrm{PH}$ ). The protective belt (PB) in Chang and Chiu's (2008) adoption of the Lakatos model (Table 1) represents the "weighing" process whereby students consider counterarguments and extensions to their own arguments and then suggest ways of addressing these issues in their SSI argumentation. The individual students' claims and supporting reasons (which form the "hard core" of their arguments) were identified from the decision-making forms they submitted, while the $\mathrm{PH}$ and $\mathrm{NH}$ used in their argumentation were identified from the transcriptions of the group discussions and their argumentative essays.

In the study of Chang and Chiu (2008), skills of informal argumentation were analyzed exclusively by considering participants' written arguments, and there was no exercise involving interaction between students that was designed to stimulate the development of evaluation skills. The 2008 study thus featured a separate assessment to evaluate participants' weighing skills; no such assessment was required in this case since the new six-step SSI instructional module (Fig. 1) aims to create a forum that encourages students to interact with one another and discuss their arguments actively. The instructional module was thus designed to encourage all of the participating students to reach a decision on the issue, to clearly identify the reasons that supported their decision, and to develop their skills of evaluation by engaging in a weighing process based on group discussion and the writing of an argumentative essay explaining their position.

A general inductive approach of the type described by Thomas (2006) was used to answer research question 2, which concerns the relationships between decisive knowledge, value, and experiences in the students' SSI argumentation. Inductive analysis enabled us to identify significant themes in the raw data without the constraints imposed by structured methodologies and prior assumptions. The inductive analysis included several rounds of reading the transcripts of the group discussions and the decision-making forms by the first and second author, independently identifying emergent themes. The aspects of knowledge, values, and experiences (which relate to students' intellectual baggage) stemming from different subject areas and considerations (e.g., sociology/culture, ethics, environment/ecology, economy, science, and policy) were identified from both the students' written arguments and the transcripts of the group discussions (cf. Chang Rundgren and Rundgren 2010; Christenson et al. 2012). To identify individual students' decisive values and the experiences that guided their use of particular pieces of knowledge and argumentation patterns, we looked for personal value statements including risk perceptions, socio-political evaluations, and other statements that could be related to the decision-making process (Kolstø 2006). The inductive analysis was 
applied to the students' written submissions (i.e., the decision-making forms), the transcripts of the group discussions, and the records of the individual interviews in order to identify the decisive values and experiences that underpinned each participating student's decisions.

\subsection{The Reliability of the Analyses}

The reliability of our analysis was ensured in two ways. First, the data gathered during this work were coded by the first and second authors independently, using the analytical framework of Chang and Chiu (2008) as discussed above and the inductive approach as described by Thomas (2006). Second, after the two separate analyses had been compared and a consensus established, the third author examined the resulting coding to validate it by a process of "investigator triangulation." A few discrepancies were identified and discussed by all three authors, leading to the establishment of a final consensus.

\section{Findings}

All seven students who participated in our study were able to take different arguments into account while making their own individual decisions on the Baltic Sea fish contamination issue. The interactions between students who took different positions also demonstrated a democratic process of the sort that is valued in modern society. The results of this study are discussed in more detail in the following sections.

\subsection{All of the Students Demonstrated Evaluation Skills}

Table 2 shows quotations from all seven participating students demonstrating their ability to take counter-arguments $(\mathrm{NH})$ into account and to extend their arguments $(\mathrm{PH})$ by presenting different viewpoints favoring their claims. Because the issue examined in the SSI teaching exercise involves science, the environment, cultural and economic factors, ethics, and policy, all seven students' arguments explored some of the multi-disciplinary aspects of this issue. The quoted comments also show that the students were capable of productively evaluating different kinds of information and using it to inform their decision-making.

Interestingly, some of the participating students used the same information to support opposing claims (i.e., one use some data to support an argument that the exemption was good while another used the same data to argue that it was bad). The background information was supplied by the teacher before the students started discussing the issue. For example, the point that using contaminated fishes to produce animal fodder might reduce overall levels of toxicity in human food was mentioned by Maria and Jenny who decided that the exemption was wrong, but as well by Andreas who was one of the three students supporting the exemption.

Jenny: "Instead of Swedes eating the toxin fishes, an option would be to use it as fodder, since most of the toxins disappear in the process of producing fodder."

Andreas: "When dioxin fish becomes fodder the levels of dioxins decreases drastically. Therefore, not all high level dioxin fish need to be sold in the fish market. A certain proportion of the total fishing can go to animal fodder and by that help feed other animals that can give people food."

The background information supplied by the teacher included evidence from a survey showing what proportion of the public was aware of the EU regulations on dioxin 
Table 2 The seven students' decisions and the positive and negative heuristics shown in their argumentations

Student Positive heuristics (PH) Negative heuristics (NH)

Decision: Exemption was wrong

Maria -Using the fishes with toxin as animal fodder could lower the level of toxicity.

-If the fish are left for themselves for a couple of generations, the concentration of dioxins would decrease.

Jenny -Because of the EU limits, we are not allowed to export this fish, so from an economical perspective, it is very small money for society as a whole.

- The fish could be used as fodder, since the concentration of toxins decrease in the process of producing fodder.

-Smaller fish could be used to produce fermented herring.

-Through the exemption, a tolerance and acceptance of the condition with environmental toxins is developed in society, which is not good.

-In the long run, we do not know how dioxins will affect us.

Hanna -If fish with too high dioxin content would be allowed to be sold, approximately $73 \%$ of the families with children would receive too high concentrations of dioxins. This could cause cancer, decreased immune defense and fertility problems.

-Through not having an exemption, a higher pressure would be put on the industries responsible for the dioxin emissions to reduce the emissions.

Peter -Even though fatty fish is healthy, there are possibilities of eating fatty fish without exposing oneself to dioxins.

-Instead of herring from the Baltic Sea, there is herring from the west coast, cultivated salmon and fish-oil.

-Even if there is information available, many people are still not informed.

Decision: Exemption was right

David -Parents of small children have the same responsibility to avoid eating toxic fish as they have to avoid drinking alcohol.

-Individuals have a responsibility to inform themselves and have a look-out for toxic products.

-It is easy for the agency to spread information by ICT and it is easy for citizens to search information.

-Decrease in amounts of dioxins in the ecosystems will reduce the concentration of toxins in top predators.

- If we were more dependent on fishing for our food supply, the situation would have been different.
-More cases of dioxin-related diseases would stimulate more medical research on these diseases.

-Cultural aspects such as fermented herring and viable coastal areas.

-It is mainly fisherman families who consume large amounts of this fish.

-I am okay to reconsider my decision, if enough information reaches the public.

-Dioxins are not dangerous in small enough concentrations, and as long as you possess the knowledge, there should be no danger.

-An argument for the exemption is the fisheries would be negatively affected. However, the calculations show that the fishermen are hardly affected et al.l.

-In the short time-scale, there are small positive economic effects of the exemption. But people's health is risked in the long run.

-The health risks posed by dioxins and PCB are evidently not as harmful compared to many other risks, but can still affect a few ill-fortuned individuals.

-If a pregnant women eats fish everyday she would consume more than recommended, which would likely harm the woman and her offspring

-The national food agency is responsible for informing, and if they do a better job there would less risk attached to this exemption. 
Table 2 (continued)

\begin{tabular}{|c|c|c|}
\hline Student & Positive heuristics $(\mathrm{PH})$ & Negative heuristics $(\mathrm{NH})$ \\
\hline Andreas & $\begin{array}{l}\text {-Marking (like on tobacco) could be an } \\
\text { alternative. } \\
\text {-If people considered the fish too dangerous, it } \\
\text { will eventually go out of the market. } \\
\text {-The tradition of eating fermented herring would } \\
\text { disappear if the exemption did not exist. } \\
\text {-A certain amount could go to fodder, which } \\
\text { would help to raise animals that will provide } \\
\text { food to people. } \\
\text {-If fishing is limited, fishermen would lose their } \\
\text { jobs and the rural areas would be highly } \\
\text { affected. }\end{array}$ & $\begin{array}{l}\text {-Many people are not aware of the risks related to } \\
\text { the consumption of fish and dioxins. Therefore, } \\
\text { many Swedes eat dangerous fish without being } \\
\text { aware of it. }\end{array}$ \\
\hline Mikael & $\begin{array}{l}\text {-The whole industry producing fermented herring } \\
\text { would have to close down without the } \\
\text { exemption. } \\
\text { - There are recommendations and information } \\
\text { about the risks connected with consumption of } \\
\text { fish which contains amounts of dioxins that } \\
\text { exceed the threshold level. } \\
\text {-From an environmental perspective the } \\
\text { exemption can be positive since Sweden does } \\
\text { not need to import fish which would entail } \\
\text { long-distance transports. }\end{array}$ & $\begin{array}{l}\text {-Health risks are among the most important } \\
\text { counter-arguments. Dioxins are dangerous for } \\
\text { the body, can give rise to everything from a } \\
\text { lack of vitamin A to cancer. } \\
\text {-The problem is that the information has not } \\
\text { reached the public. But it is the responsibility of } \\
\text { the individual to keep track of what he or she } \\
\text { consumes. } \\
\text { - Is it right that the state and some people make a } \\
\text { profit from the exemption? This is the case also } \\
\text { with other products. Even if this might not be } \\
\text { ethically right, this is the situation today and } \\
\text { we must therefore accept it. }\end{array}$ \\
\hline
\end{tabular}

consumption and Sweden's exemption. This evidence was similarly used both in support of and opposition to the exemption. For example, David supported the exemption and stated that individuals are responsible for investigating the food they eat and its toxicity, despite knowing that the public was largely unaware of the information. However, he did state that the food agency could improve its communication and thus reduce the risk to public health posed by dioxin-contaminated fish:

David: "Individuals have a responsibility to inform themselves and have a look-out for toxic products....It is easy for the agency to spread information by ICT and it is easy for citizens to search information. The national food agency is responsible for informing, and if they do a better job there would less risk attached to this exemption."

Maria drew on her own experiences to support her position that the exemption was wrong:

Maria: "Sweden's public health will decline because of the exemption. Due to the poor labeling and poor information available, the consumption of dioxin fish will lead to a deterioration of the public health in Sweden. Dioxins affect the brain, the endocrine system, and may cause cancer and so on. In addition dioxins is stored in fat, which means that they do not leave the body quickly.......Personally, I knew nothing about this risk before we discussed it in school, and I believe that the government is gambling with the public health. Eating more than 2-3 fishes with high levels of dioxins per year is a major health hazard."

The finding that the same piece of information can be used to support diametrically opposed claims illustrates that individuals' personal values influence what decisive knowledge will be used to make arguments relating to SSI, which is consistent with the results regarding the interplay between decisive knowledge and decisive values obtained by Kolstø (2006). The 
following section discusses the relationships between decisive values, knowledge, and experiences in the students' argumentation on toxic fish and the exemption issue.

\subsection{The Exploration of Decisive Values and Decisive Knowledge}

In general, students' personal experiences did not seem to have a strong influence on their decision-making concerning Sweden's exemption and the dioxin contamination of fish from the Baltic. None of the students mentioned any personal connections to professional fishing, and the personal experiences they referred to mainly related to experiences as consumers. Their SSI argumentation was therefore primarily governed by decisive values and decisive knowledge.

The previous section demonstrated that specific pieces of knowledge (dioxins can accumulate in the human body and cause cancer) and evidence (the finding that the public was generally unaware of the toxicity of fish from the Baltic Sea) were used by students to support very different claims. We argue that the students' decisive values were determined by the intellectual baggage they brought into the classroom. As shown in Fig. 2, based on the students' claims, we grouped the seven students into two groups-YES (students who supported the exemption) and NO (those who opposed it).

The NO group included Peter, Jenny, Maria, and Hanna. The other three male students formed the YES group and supported the exemption. The decisive values of the students who opposed the exemption centered on the unknown but potentially severe long-term risks of dioxin consumption.

Jenny: "The long term effects of dioxins are relatively unknown, and we do not have much knowledge about the subject. Dioxins are suspected to cause some forms of cancer and affect the immune system, endocrine system, reproductive ability, and higher doses can affect the brain and nervous system.......'Besides affecting us today with not yet fully known consequences, all future generations will also be affected. A woman exposed to toxins such as dioxins, accumulate them and transfer the dioxins via the placenta and breast milk to her child. Therefore, the levels of dioxins in individuals will increase for each generation. It is known that we can tolerate a certain level of intake, but how will this affect us, if we already have dioxins from our mothers and perhaps simultaneously are exposed to other toxins."

Peter: "Dioxins constitute a threat. Dioxins are found in small invisible amounts. However, it is toxic even in small quantities. This means that dioxins represent an invisible threat.

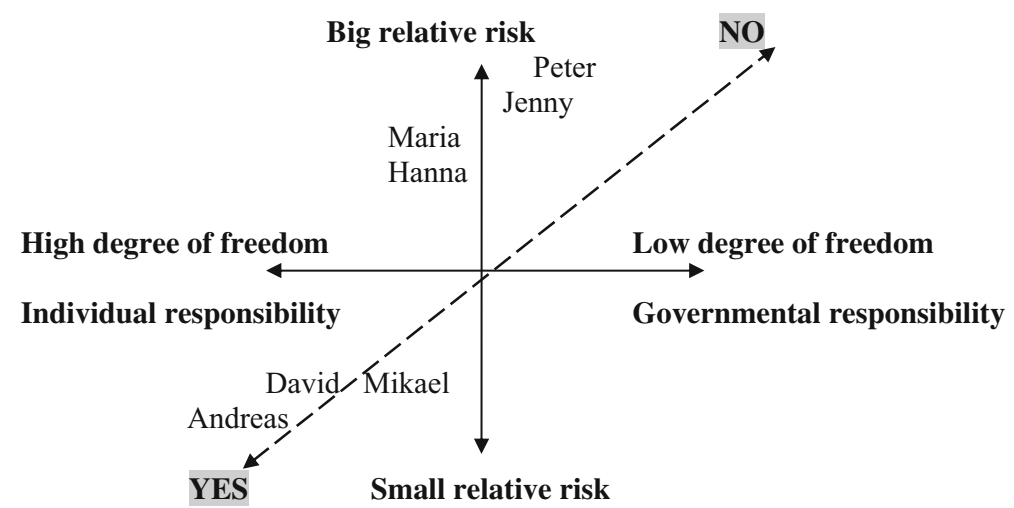

Fig. 2 A two-dimensional representation of the students' decisive values 
Dioxins must be met with caution. We must not be soft, and because the threat is invisible we must take the utmost precautions...... there are other toxins in the environment as well, similar to dioxins but coming from completely different sources. Nobody knows what happens when they are mixed together."

The evidence that information about dioxin levels in fish from the Baltic Sea had not been widely disseminated to the public was very concerning to students in the NO group, all of whom stated that the government and its agencies are responsible for protecting people's health and should therefore have blocked the exemption.

Jenny: 'It's a shame because if there was enough information, that's there's already enough information, but if everyone would get that information, maybe I would think it was okay they [the Swedish government] made that decision.......Some [arguments supporting the exemption] are pretty silly. But generally, as you [David] said, if the population would be informed, this exemption would maybe not cause any huge risks. But that's only if the entire Swedish population would follow the [fish-eating] recommendations that exist."

Hanna: "The National Food Agency has for years tried to spread the information of the risks of dioxins in fish and tell people about the fish eating recommendations. Despite this effort, only $27 \%$ of all families and $18 \%$ of the population know about these recommendations. This means, that if we allow selling of fish with high levels of dioxins in the shop, approximately $73 \%$ of all families with children would get too high levels of dioxins, which could lead to that the children's children might be born with cancer, impaired immune system or make it impossible for them to have children, due to the exposure of high levels of dioxins in the breast milk and during their childhood which have destroyed their reproductive systems."

While Peter and Jenny seemed to be relatively firm in their claim that the exemption was wrong, Maria and especially Hanna seemed less certain about their claim, and they both said that they found it hard to make a decision. In the group discussion, Hanna presented arguments both for and against the exemption, and on several occasions, she openly expressed her difficulty in making a decision:

Hanna: “...it's hard to make a decision... First we take the positive [arguments], then we compare them to the negative ones and we end up nowhere."

Similarly, in the individual interviews, Hanna stated that the group discussion made her reevaluate her first opinion and that her ideas and decision were influenced by the discussion. At the end, Hanna seems to have come to the conclusion that there are more cons than pros, and therefore took the view that it was wrong for the Swedish government to accept the permanent exemption:

Hanna: "It's just too big risks with the exemption and too few advantages to allow the fishing."

Interestingly, the three students who supported the exemption all used tobacco and alcohol as examples to support the sale of potentially toxic fish in Sweden, even though the three students were not all in the same discussion group. They argued that tobacco and alcohol are both harmful to human health but remain legal to sell, so the same should go for toxic fish. These students valued the human right of freedom of choice in consumption and considered the health risks of dioxins to be comparatively small.

David: "The health hazard that dioxin and PCBs represent is obviously not as intimidating compared to many other threats, but can anyway of course affect a few unfortunate individuals. The damage caused when taking a schnapps to the food at the Swedish midsummer celebration is probably much greater than those caused by eating one or two sandwiches with fermented 
herring.......There is considerably worse health hazards than dioxins and PCBs, and they are only limited by an age limit, e.g. tobacco and alcohol. As long as legal drugs are sold by the state, the exemption should not be abolished.....Parents of young children have the same responsibility to choose not eating fish with high dioxin levels as women should abstain consuming alcohol and tobacco during their pregnancy. What you consume is highly your own active choice and the dangers of consuming the wrong goods can easily be avoided."

Andreas: "However, to just make prohibitions are rarely good solutions. Instead, the government could introduce regulations about labeling dangerous fish, similar to the marking of products that contain tobacco and alcohol: A label that points out the dangers and how often the fish can be consumed without being harmful to the human body. Citizens may then decide for themselves whether they want to eat that kind of fish and how often. Today, similar regulations are applied to other hazardous products sold on the Swedish market."

For these students, the point that many members of the public were unaware of the toxicity of fish from the Baltic Sea was not a problem because people are responsible for seeking out such information themselves.

Mikael: "We can't say that information is not available. There are recommendations and information about the risks connected with consumption of fish with high levels of dioxins."

In addition, the students suggested that the health risks presented by the fish would become less severe if people knew they contained toxins because they would stop buying such fish, so the market would solve the problem:

Andreas: "Such a solution would also mean that the market would control the fish selling, not the government or the EU. If some people are willing to eat fish with high dioxin levels, different fisheries will be able to sell their fish and continue to run their business. If not, they will lose customers and be forced to shut down, but then only because there is no longer any market for such fish. The inhabitants of Sweden have to make a constant active choice about how fish with high dioxin levels will be managed."

In order to decide whether the government was right or wrong to accept the permanent exemption from the EU regulations governing dioxin levels for fatty fish from the Baltic Sea, the students were obliged to assess an uncertain health risk and weigh this health risk against other values. The students used a wide range of information and knowledge from subject areas such as science, ecology and environmental studies, economics, and sociology as well as cultural factors. Because of the group discussions, all of the students had access to the same information when making their decisions. The students thus handled the evaluation and weighing of different pieces of information in different ways.

However, the information about the health risks and the failure to communicate the health agency's recommendations about fish consumption to the general public seemed to be decisive for all students. This allowed us to identify two main decisive values that governed the students' ultimate decisions (claims). The first one relates to their estimates of the health risk posed by toxic fish consumption relative to other risks (i.e., the magnitude of the relative risk). The other relates to their views about who is responsible for ensuring that consumers are aware of and adhere to the government's recommendations concerning fish consumption. This relates to individuals' freedom to choose what to consume and the state's responsibility to control and secure its citizens' health. An individual's stance with respect to these two decisive values can be visualized using a two-dimensional plot with one axis corresponding to an estimated risk dimension that reflects the magnitude of the relative risk as estimated by the individual in question, and a responsibility dimension that reflects the individual's view of who is responsible for providing and assimilating information about dioxins in fish and avoiding 
overconsumption of such hazardous food (Fig. 2). Figure 2 gives some indications of gender differences in students' argumentation, since the male students (all except Peter) tend to cluster more toward the "low risk" assessment end of the axis, while the female students cluster more toward the "high risk" assessment end.

The individual students' evaluations of decisive knowledge during their decision-making seem to have been guided by their different moral beliefs and values. Thus, to understand why some information is relevant to some students but not to others, it is important to understand the nature of these different guiding beliefs and values. The students who stated in the interview that they quickly made a decision and did not change it during the group discussions must have found knowledge they considered relevant and which could be reconciled straightforwardly with their existing beliefs and personal experiences in a way that supported their decisive values. This was presumably the case for Jenny and Peter, who quickly focused on the high health risks presented by dioxin contamination and the need for regulatory controls to protect human health. However, it was also presumably true for Andreas, David, and Mikael, who estimated the health risk to be relatively low compared to other risks and believed in people's ability to make informed and healthy decisions on their own. In light of Sadler and Zeidler's (2005) concepts of rationalistic, emotive, and intuitive forms of informal reasoning, these students' quickly-made decisions seem at first hand to be relatively intuitive "gut-level" reactions based on their pre-existing personal values and experiences (intellectual baggage). This hypothesis is also supported by Sadler and Zeidler's conclusion that if a person expresses an intuitive reaction to an issue then they will almost always use this reaction as a guide in their final decision-making, regardless of other concerns. On the other hand, all students' arguments contained a lot of rationalistic reasoning (as defined by Sadler and Zeidler), and none of the students' decision-making processes could reasonably be characterized as being based on intuitive reasoning alone. However, the intuitive reactions demonstrated by the students' early decisions may reflect their guiding beliefs associated with the issue, which in turn determine how they evaluate and weigh information to select data that will be considered important and identify information that does not support the intuitive standpoint or cannot be used to defend it.

\section{Conclusions and discussion}

All seven students who participated in our study had access to the same information but nevertheless weighed this information differently. These different weightings reflected the differences in their core beliefs (Kolstø 2006) and their intellectual baggage (Zeidler 1997). The students were divided into two groups based on the similarity of their arguments. The first group, consisting of David, Mikael, and Andreas, claimed that "the exemption is right." They all acknowledged the health risks associated with excessive consumption of fish containing dioxins, but placed a greater weighting on the right of individual consumers to freely choose what they would eat - they regarded this as a decisive value that overrode the health risks of eating contaminated fish. All three argued that the health risks of consuming fatty fish should be compared to those presented by other legal products such as alcohol or tobacco, thereby introducing a relativistic view of the risks presented by dioxin-contaminated fish. While they acknowledged that some social groups were unaware of the risks presented by the fish, they stated that it is the individual responsibility of the consumer to obtain such information. They also assigned some weight to the economic and cultural arguments supporting the exemption. 
The other group consisted of the remaining four students and claimed that "the exemption is wrong." They weighted the health-risk argument heavily enough for it to override all other concerns; this was especially evident in the argumentation of Jenny and Peter. They did not consider economic and cultural arguments to be at all as weighty as the health risks. Although the number of students in the study may be too low to say anything about gender differences in students' argumentation, female students seemed to ascribe more weight to health risks in their argumentation than male students.

The students in this group seemed to embrace the view that the government authorities have a special responsibility to inform citizens about health risks and protect them from harm. However, as also found by Kolstø (2006), some of the students in this group found it hard to make a decision. The students in this study generally acknowledged counterarguments to their claims and some (like Jenny) indicated that they would be prepared to change their decision if the situation changed - for instance if the risks of eating contaminated fish were more widely known. Nevertheless, most of the students were able to weigh the available information, decide that some aspects were more important than others, and reach a decision. However, Maria and especially Hanna found this hard; they listed arguments for and against the exemption and stated that it was hard to determine which ones were more important. The Baltic Sea fish issue did not seem to trigger any special value or experience from their intellectual baggage, and they ended up listing different pieces of information about the case without being able to weigh them with respect to any particular decisive value.

The results obtained during the six-step SSI instructional module clearly showed that it can be used to deal with authentic, complex SSI (such as the issue of dioxin-contaminated fish and Sweden's exemption) in upper secondary classrooms. The analysis of the characteristics of students' evaluation skills show that the module's instructional design allowed students to develop a meta-awareness of the diverse factors that influence issues of this sort, and to recognize that other people may value and weigh arguments in different ways. The students' use of negative heuristics in their argumentation showed that the SSI teaching design was successful in making them address and discuss counterarguments to their chosen positions. The finding of Evagorou et al. (2012) that students tended to focus on evidence that supported their position and ignore that which did not was not replicated in this case. However, our data do not provide clear evidence that the use of NH increased the quality of the arguments presented by individual students. NH were particularly evident in the argumentation of Hanna and Maria, who weighed the different arguments and discussed their cons carefully. However, they seemed to have difficulties in reaching a conclusion. On the other hand, Jenny and David found it very easy to make a decision. While they took the counterarguments to their position into account, they seemed to argue from specific value-based standpoints that allowed them to quickly allocate greater weight to some arguments than others and thereby reach a firm decision.

This study demonstrated the feasibility of using complex societal issues in science teaching, allowing students to develop their awareness of diverse aspects and skills involved in resolving SSI through a multi-disciplinary instructional model (Chang Rundgren 2011). The design of the multi-disciplinary SSI exercise was clearly helpful in scaffolding the students' SSI discussions and students' evaluation skills were induced and demonstrated in their final individual SSI argumentations. Using SSI necessarily opens up science lessons to argumentation and the incorporation of knowledge from various non-scientific areas. Crucially, values play a role in SSI argumentation that is very different to that usually encountered in science classrooms. This may be challenging for science teachers and needs to be addressed in teacher professional development programs. 
The students claiming that the exemption was right based their arguments on values of individual freedom and consumer rights rather than knowledge of scientific data. However, we cannot say that their arguments were invalid in the context of the assignment or that they were of inferior quality from a scientific point of view because they also acknowledged the scientific information that was provided for discussion. In a democratic society that embraces pluralistic views on teaching (Öhman 2006; Rudsberg and Öhman 2012), we need to acknowledge different kinds of views and perspectives. However, we also need to help students to widen their perspectives from the well-known local conditions of their everyday world and to develop the ability to take regional, global, and long-term perspectives into account. Furthermore, questions about people's equity and health and the well-being of the ecosystems we depend on become acute when dealing with issues relating to sustainable development. School education has far-reaching potential to influence not only the knowledge that students develop but also the dominant perspectives and values in society. In today's society, students need opportunities to practice democratic action in different contexts during their education and to experience different values and perspectives when addressing SSI. It is also important for students to listen to their peers expressing other views. However, it remains to be determined how best to ensure that education in schools will help students to broaden their perspectives in a way that will both benefit them as individuals and equip them to contribute to a more sustainable future.

The explorative nature of the present study, with non-generalizable findings, calls for future research to be conducted on the use of complex SSI in the classroom. It would be possible to use the six-step instructional module presented here on other issues and with different, and larger, groups of students. The results from such studies could increase our understanding of the feasibility of using complex societal issues in the classroom and of the characteristics of students' argumentation among different groups of students.

Conflict of interest The authors certify that there is no actual or potential conflict of interest in relation to this article.

Open Access This article is distributed under the terms of the Creative Commons Attribution 4.0 International License (http://creativecommons.org/licenses/by/4.0/), which permits unrestricted use, distribution, and reproduction in any medium, provided you give appropriate credit to the original author(s) and the source, provide a link to the Creative Commons license, and indicate if changes were made.

\section{References}

Acar, O., Turkmen, L., \& Roychoudhury, A. (2010). Student difficulties in socio-scientific argumentation and decision-making research findings: crossing the borders of two research lines. International Journal of Science Education, 32(9), 1191-1206.

Bell, R. L., \& Lederman, N. G. (2003). Understandings of the nature of science and decision making on science and technology based issues. Science Education, 87(3), 352-377.

Chang, S.-N., \& Chiu, M.-H. (2008). Lakatos' scientific research programmes as a framework for Analysing informal argumentation about socio-scientific issues. International Journal of Science Education, 30(13), $1753-1773$.

Chang Rundgren, S.-N. (2011). Post it! - a cross-disciplinary approach to teach socioscientific issues. Teaching Science, 5(3), 25-28.

Chang Rundgren, S.-N. \& Rundgren, C.-J. (2010). SEE-SEP: From a separate to a holistic view of socioscientific issues. Asia-Pacific Forum on Science Learning and Teaching, 11(1), Article 2. 
Christenson, N., \& Chang Rundgren, S.-N. (2015). A framework for teachers' assessment of socio-scientific argumentation: an example using the GMO issue. Journal of Biological Education, 49(2), 204-212.

Christenson, N., Chang Rundgren, S.-N., \& Höglund, H.-O. (2012). Analysing upper secondary students' use of supporting reasons in arguing socioscientific issues through the SEE-SEP model. Journal of Science Education and Technology, 21(3), 342-352.

Christenson, N., Chang Rundgren, S.-N., \& Zeidler, D. (2014). The relationship of discipline background to upper secondary students' argumentation on socioscientific issues. Research in Science Education, 44(4), 581-601.

Davidov, E., Schmidt, P., \& Schwartz, S. H. (2008). Bringing values back in: the adequacy of the European social survey to measure values in 20 countries. Public Opinion Quarterly, 72(3), 420-445.

Dewey, J. (1916). Democracy and education. New York: Macmillan.

Driver, R., Newton, P., \& Osborne, J. (2000). Establishing the norms of scientific argumentation in classrooms. Science Education, 84, 287-312.

Erduran, S., Simon, S., \& Osborne, J. (2004). TAPping into argumentation: developments in the application of Toulmin's argument pattern for studying science discourse. Science Education, 88(6), 915-933.

Eriksson, M., \& Rundgren, C.-J. (2012). Vargfrågan - Gymnasieelevers argumentation kring ett sociovetenskapligt dilemma. [The wolf issue - upper secondary students' argumentation about a socioscientific issue]. NorDiNa (Nordic Studies in Science Education), 8(1), $26-41$.

Evagorou, M., Jimenez-Alexandre, M. P., \& Osborne, J. (2012). 'should We kill the Grey squirrels?' a study exploring students' justifications and decision-making. International Journal of Science Education, 34(3), 401-428.

Fleming, R. (1986). Adolescent reasoning in socio-scientific issues, part I: social cognition. Journal of Research in Science Teaching, 23(8), 677-687.

Grace, M. M., \& Ratcliffe, M. (2002). The science and values that young people draw upon to make decisions about biological conservation issues. International Journal of Science Education, 24(11), 1157-1169.

Kelly, G. J., Druker, S., \& Chen, C. (1998). Students' reasoning about electricity: combining performance assessments with argumentation analysis. International Journal of Science Education, 20(7), 849-871.

Kolstø, S. D. (2001). Scientific literacy for citizenship: tools for dealing with the science dimension of controversial socioscientific issues. Science Education, 90, 632-655.

Kolstø, S. D. (2006). Patterns in students' argumentation confronted with a risk-focused socioscientific issue. International Journal of Science Education, 28(14), 1689-1716.

Kolstø, S. D., \& Ratcliffe, M. (2007). Social aspects of argumentation. In S. Erduran \& M. P. Jiménez-Aleixandre (Eds.), Argumentation in science education: perspectives from classroom-based research (pp. 117-136). Dordrecht, the Netherlands: Springer.

Lakatos, I. (1978). The methodology of scientific research programmes. New York: Cambridge University Press.

Levinson, R. (2006). Towards a theoretical framework for teaching controversial socio-scientific issues. International Journal of Science Education, 28(10), 1201-1224.

Liu, S.-Y., Lin, C.-S., \& Tsai, C.-C. (2011). College students' scientific epistemological views and thinking patterns in socioscientific decision making. Science Education, 95(3), 497-517.

López-Facal, R., \& Jiménez-Aleixandre, M. P. (2008). Identities, social representations and critical thinking. Cultural Studies in Science Education, 4(3), 689-695.

Means, M. L., \& Voss, J. F. (1996). Who reasons well? Two studies of informal reasoning among children of different grade, ability, and knowledge levels. Cognition and Instruction, 14(2), 139-178.

Morris, H. (2014). Socioscientific issues and Multidisciplinarity in school science textbooks. International Journal of Science Education, 36(7), 1137-1158.

Nielsen, J. A. (2012a). Science in discussions: an analysis of the use of science content in science content in socioscientific discussions. Science Education, 96(3), 428-456.

Nielsen, J. A. (2012b). Co-opting science: a preliminary study of how students invoke science in value-laden discussions. International Journal of Science Education, 34(2), 275-299.

Nielsen, J. A. (2013). Dialectical features of students' argumentation: a critical review of argumentation studies in science education. Research in Science Education, 43(1), 371-393.

Öhman, J. (2006). Pluralism and criticism in environmental education for sustainable development: a practical understanding. Environmental Education Research, 12(2), 149-163.

Osborne, J., Erduran, S., \& Simon, S. (2004). Enhancing the quality of argumentation in school science. Journal of Research in Science Teaching, 41(10), 994-1020.

Oulton, C., Dillon, J., \& Grace, M. (2004). Reconceptualizing the teaching of controversial issues. International Journal of Science Education, 26(4), 411-423.

Railton, P. (2014). The affective dog and its rational tale: intuition and attunement. Ethics, 124(4), 813-859.

Rudolph, J. L. (2005). Inquiry, instrumentalism, and the public understanding of science. Public Understanding of Science, 89(5), 803-821.

Rudsberg, K., \& Öhman, J. (2012). Pluralism in practice - experiences from Swedish evaluation, school development and research. Environmental Education Research, 16(1), 95-111. 
Rundgren, C.-J. \& Eriksson, M. (2014) Umweltgifte in Fischen aus der Ostsee - Eine Strategie zum Umgang mit Kontroversen Fragestellungen im naturwissenschaftlichen Unterricht aus PROFILES in Schweden. [Environmental toxins in fish from the Baltic Sea - A strategy to deal with controversial issues in science education from PROFILES in Sweden] Der Mathematische und Naturwissenschaftliche Unterricht, 67(6), 332-336.

Sadler, T. D. (2004). Informal reasoning regarding socioscientific issues: a critical review of research. Journal of Research in Science Teaching, 41(5), 513-536.

Sadler, T. D., \& Zeidler, D. (2005). Patterns of informal reasoning in the context of socioscientific decision making. Journal of Research in Science Teaching, 42(1), 112-138.

Sadler, T. D., \& Zeidler, D. L. (2009). Scientific literacy, PISA, and socioscientific discourse: assessment for progressive aims of science education. Journal of Research in Science Teaching, 46(8), 909-921.

Sadler, T. D., Barab, S. A., \& Scott, B. (2007). What do students gain by engaging in socioscientific inquiry? Research in Science Education, 37(4), 371-391.

Shafir, Simonson, \& Tversky (1993). Reason-based choice. Cognition, 49, 11-36.

Simonneaux, L., \& Simonneaux, J. (2009). Socio-scientific reasoning influenced by identities. Cultural Studies in Science Education, 4(3), 705-711.

Stuckey, M., Hofstein, A., Mamlok-Naaman, R., \& Eilks, I. (2013). The meaning of 'relevance' in science education and its implications for the science curriculum. Studies in Science Education, 49(1), 1-34.

Swedish National Agency of Education (2011). Curriculum for the upper secondary school 2011. Stockholm: Swedish National Agency of Education.

Swedish National Food Agency. (2011). Redovisning av regeringsuppdrag rörande gränsvärden för långlivade miljöföroreningar i fisk från Östersjöområdet. [Description relating to Limit Values for Persistent Environmental Contaminants in Fish from the Baltic Sea Region.] Report. Swedish National Food Agency, Dnr 115/2010. http://www.slv.se/upload/dokument/remisser/regeringsuppdrag_2011/rapport_ regeringsuppdrag_dioxinundantag_2011_02_28.pdf (10.07.2013).

Thomas, D. R. (2006). A general inductive approach for analyzing qualitative evaluation data. American Journal of Evaluation, 27(3), 237-246.

Toulmin, S. (1958). The uses of argument. Cambridge, England: Cambridge University Press.

Voss, J. F., \& Means, M. L. (1991). Learning to reason via instruction in argumentation. Learning and Instruction, 1, 337-350.

Wu, Y.-T., \& Tsai, C.-C. (2007). High school students' informal reasoning on a socio-scientific issue: qualitative and quantitative analyses. International Journal of Science Education, 29(9), 1163-1187.

Zeidler, D. (1997). The central role of fallacious thinking in science education. Science Education, 81(4), 483496. 